\title{
In Vivo Measurement of Conduction Velocities in Afferent and Efferent Nerve Fibre Groups in Mice
}

\author{
H. STEFFENS ${ }^{1}$, P. DIBAJ ${ }^{2}$, E. D. SCHOMBURG ${ }^{1}$ \\ ${ }^{1}$ Physiological Institute, University of Göttingen, Germany, ${ }^{2}$ Max-Planck-Institute for Experimental \\ Medicine, Göttingen, Germany
}

Received August 1, 2011

Accepted January 13, 2012

On-line January 31, 2012

\begin{abstract}
Summary
Electrophysiological investigations in mice, particularly with altered myelination, require reference data of the nerve conduction velocity (CV). CVs of different fibre groups were determined in the hindlimb of anaesthetized adult mice. Differentiation between afferent and efferent fibres was performed by recording at dorsal roots and stimulating at ventral roots, respectively. Correspondingly, recording or stimulation was performed at peripheral hindlimb nerves. Stimulation was performed with graded strength to differentiate between fibre groups. CVs of the same fibre groups were different in different nerves of the hindlimb. CVs for motor fibres were for the tibial nerve $(\mathrm{Tib}) 38.5 \pm 4.0 \mathrm{~m} / \mathrm{s}(\mathrm{A} \gamma: 16.7 \pm 3.0 \mathrm{~m} / \mathrm{s})$, the sural nerve (Sur) $39.3 \pm 3.1 \mathrm{~m} / \mathrm{s}(12.0 \pm 0.8 \mathrm{~m} / \mathrm{s})$ and the common peroneal nerve (Per) $46.7 \pm 4.7 \mathrm{~m} / \mathrm{s}(22.2 \pm 4.4 \mathrm{~m} / \mathrm{s})$. CVs for group I afferents were $47.4 \pm 3.1 \mathrm{~m} / \mathrm{s}$ (Tib), $43.8 \pm 3.8 \mathrm{~m} / \mathrm{s}$ (Sur), $55.2 \pm 6.1 \mathrm{~m} / \mathrm{s}$ (Per) and $42.9 \pm 4.3 \mathrm{~m} / \mathrm{s}$ for the posterior biceps (PB). CVs of higher threshold afferents, presumably muscle and cutaneous, cover a broad range and do not really exhibit nerve specific differences. Ranges are for group II $22-38 \mathrm{~m} / \mathrm{s}$, for group III $9-19 \mathrm{~m} / \mathrm{s}$, and for group IV 0.8-0.9 m/s. Incontrovertible evidence was found for the presence of motor fibres in the sural nerve. The results are useful as references for further electrophysiological investigations particularly in genetically modified mice with myelination changes.
\end{abstract}

\section{Key words}

Mouse nerves • Nerve fibre groups • Conduction velocity • Sural motor efferents

\section{Corresponding author}

E. D. Schomburg, Physiological Institute, University of Göttingen, Humboldtallee 23, D-37073 Göttingen, Germany. Fax: ++49 551 395923. E-mail: eschomb@gwdg.de

\section{Introduction}

In recent years, the mouse with its high reproduction rates and short gestation times has gained a lot of scientific attention within the field of neuroscience, especially with the use of transgenic varieties. In addition, mouse models exist for a variety of human diseases with hereditary backgrounds. In principle, these models for neurological diseases are an ideal tool for in vivo neurological screening and investigations on the phenotypic appearance of the disease. However, in vivo electrophysiological studies in mice are rare, because of the delicate preparations required and the difficulties in keeping anaesthetized mice alive long enough. Often, accuracy of the measurements may be afflicted by gross simplification of the methods. For example, the range of fastest conduction velocities (CV) of afferents from the hindlimb was stated as to be $10-100 \mathrm{~m} / \mathrm{s}$ (Biscoe et al. 1977), down to $11.2 \pm 5.3 \mathrm{~m} / \mathrm{s}$ (Yoshida and Matsuda 1979). Even though the CV of the fastest motor efferents (A $\alpha$ fibres) in different mice strains should not vary too much (Tabata et al. 2000), the measurements on CV of motor efferents of the hindlimb of wild type mice have generated a wide range of different values (Toyoshima et al. 1986, Huxley et al. 1998, Ng et al. 1998, Wallace et al. 1999, Tabata et al. 2000, Weiss et al. 2001, Song et al. 2003, Haupt and Stoffel 2004). Diverging data for afferent fibre groups have also been published (Biscoe et al. 1977, von Burg et al. 1979, Yoshida and Matsuda 1979, Norido et al. 1984, Koltzenburg et al. 1997, Cain et al. 2001, Nakagawa et al. 2001), most of which have been collected in vitro. When whole nerves were tested for their conduction velocity, measurements for $\mathrm{CV}$ 
concern the fastest fibres, except for in a few cases where e.g., cutaneous fibres were identified by natural stimulation (Koltzenburg et al. 1997). A few measurements have also been made on C-fibres (Koltzenburg et al. 1997, Cain et al. 2001) or on slow unmyelinated fibres (Yoshida et al. 1979).

We have now measured for the first time CVs for different fibre groups (A $\alpha, A \gamma$, different muscle and cutaneous afferents) and for different hindlimb nerves. This differentiation has not been published or investigated before.

\section{Methods}

The experiments were carried out on 26 adult male wild type mice (C57BL/6IN), weighing 19-34 g (age: 104-151 days; mean 124 days). The set-up is based on a further development of the experimental design published by Ellrich and Wesselak (2003). Nearly the whole preparation has to be done under binocular microscope. Anaesthesia was induced with $70 \mathrm{mg} / \mathrm{kg}$ pentobarbital i.p. (dissolved in $0.9 \% \mathrm{NaCl}$ ). After about $5 \mathrm{~min}$, when the anaesthesia was deep enough to abolish the pinna reflex or the blink reflex, the animals were fixed on an adjustable heat pad. The temperature was controlled by a rectally inserted probe, thus, keeping the body temperature close to $37^{\circ} \mathrm{C}$ throughout the experiment. When needed additional heating was performed from above by a lamp (70 watt) which was positioned over the mice. The jugular vein was cannulated and anaesthesia was continued by injection of methohexital (Brevimytal, Lilly, $0.5 \%$ in $\mathrm{NaCl}$, 40-60 $\mathrm{mg} / \mathrm{kg} / \mathrm{h}$ ). Then, a tracheotomy was performed with insertion of a tracheal tube for later artificial ventilation. The ECG was recorded by two needles inserted into the forelimbs. Changes of the heart rate and temperature were used to control the anaesthetic state. A laminectomy was performed from vertebrae L1 to L5 to expose the lower spinal cord segments up to L4 and to expose the dorsal roots L4 and L5 in full length (cf. Dibaj et al. 2010, 2011).

For preparation of hindlimb nerves, the triceps surae and the posterior biceps muscle were exposed from the dorsal side and, in general, 4 nerves were prepared and mounted for stimulation or recording: nerve to posterior biceps ( $\mathrm{PB}$ ), distal tibial nerve (Tib, excluding the nerves to gastrocnemius-soleus and flexor digitorum longus), common peroneal nerve (Per), and sural nerve (Sur). Additionally, in some experiments the common sciatic nerve (Isch), which was always left in continuity, was used for stimulation or recording. $\mathrm{PB}$ is a pure muscle nerve, while Tib and Per are mixed cutaneous and muscle nerves. Sur, which in other species (cat, rat) is a pure cutaneous nerve, seems to include a small muscle nerve fraction in mice (see below). The nerves were always prepared submerged in Ringer's solution to avoid desiccation.

After this procedure, the mice were connected to artificial ventilation with a gas mixture of $\mathrm{CO}_{2}(2.5 \%)$, $\mathrm{O}_{2}(47.5 \%)$, and $\mathrm{N}_{2}(50 \%)$ at 120 strokes $/ \mathrm{min}$ (160-200 $\mu 1 /$ stroke). These values turned out to be adequate for sufficient respiration with positive pressure inspiration and passive expiration (cf. Dibaj et al. 2010, 2011).

For recording, the spine was fixed by clamps, and the prepared nerves and the spinal cord were covered with mineral oil in pools which had been formed by skin flaps. The dorsal and/or ventral roots L4 were cut and mounted for stimulation and/or recording. The fibres of the investigated nerves mostly arise from L4. In a few experiments, L5 was prepared for stimulation and/or recording, too. Recording and stimulating was performed with bipolar platinum hook electrodes. Distance between the hooks was $1.5-2 \mathrm{~mm}$. Rectangular, constant voltage stimulation pulses were used with a duration of $0.1 \mathrm{~ms}$. The interval between two successive stimuli was mostly $1.8 \mathrm{~s}$. For high threshold fibres (group III and IV), stimulation interval was enhanced to 2.8 or $3.8 \mathrm{~s}$, and the pulse duration was enhanced to 0.2 or $0.5 \mathrm{~ms}$. Stimulation strength is always given in multiples of the threshold strength for the lowest threshold fibres at the stimulation site ("T"; e.g. threshold for group II fibres is about 1.6 times of the threshold for group I fibres, i.e. 1.6T). Recording was done with a sampling rate of $40-50 \mathrm{kHz}$. The signal was appropriately pre-amplified and filtered. Bandwidths of the filters were $10 \mathrm{~Hz}$ to $100 \mathrm{kHz}$ for responses of myelinated fibres and $0.1 \mathrm{~Hz}$ to $10 \mathrm{kHz}$ for $\mathrm{C}$-fibres. Generally 8 responses were averaged for more accurate measurements.

In a few experiments the temperature was measured by a small thermoprobe (diameter less than $1 \mathrm{~mm})$ in the oil-filled pools at the spinal cord $\left(32-34{ }^{\circ} \mathrm{C}\right)$ and at the hindlimb $\left(31-33^{\circ} \mathrm{C}\right)$. In the hindlimb pool the distance from the cathode of the stimulating electrode or from the recording electrode, respectively, to the proximal entrance of the nerves into the tissue between muscles was $\leq 3 \mathrm{~mm}$. In the spinal cord pool the corresponding distance was $\leq 5 \mathrm{~mm}$. This means that maximally $8 \mathrm{~mm}$ i.e. maximally about $20 \%$ of the investigated nerves were running free through oil pools. 
To verify the presence of motor efferents in the sural nerve, in particular experiments the initially intact sural nerve was prepared, mounted and stimulated as proximal as possible. A second surface electrode was put more distally at the sural nerve for recording and a third electrode was located at the lateral edge of the foot on the exposed muscle for EMG recording. Then, the sural nerve was cut proximal to the stimulation electrode and, afterwards, first the lateral and then the medial branch of the nerve were cut and the persistence of the toe twitch and EMG potential was tested in each case.

At the end of the experiment, the length of the nerves and roots were measured in situ. For this purpose the sciatic nerve and the nerve plexus near the spine were exposed at full length, and a thin cotton thread was laid on it, up to the L4 root to measure the length. This method guaranteed neither shrinkage nor lengthening of the nerve after complete dissection. To calculate $\mathrm{CV}$, latencies from stimulus onset time to the beginning of a potential for the measured fibre group was measured to ensure calculation for the fastest fibres of the corresponding group. The calculation was always based on the distance between the stimulating cathode and the first electrode of the recording pair.

The developed set up for mice turned out to be very reliable. The experiments lasted up to $10 \mathrm{~h}$ (with a preparation time of about $2 \mathrm{~h}$ ).

The experiments comply with the guide of the National Research Council for care and use of laboratory animals and passed the ethics commission of the Medical Faculty of the University of Göttingen.

\section{Results}

\section{General findings}

$\mathrm{CV}$ was measured with the above-mentioned techniques for motor efferents and muscle and cutaneous afferents, with different fibre groups from low threshold myelinated to high threshold unmyelinated fibres. Regularly, the thresholds of the nerves and the spinal cord roots were between 50 and $100 \mathrm{mV}$, and the time difference between the front of the response potential and the rising edge of the stimulus was taken as conduction time. Utilization time of the stimulus was not considered, however, measurements were always done on responses elicited by a stimulus 1.5-2 times higher than the threshold of the corresponding fibre group. Measurement of the response latency with stimulation above 1.5-2 times threshold of the corresponding fibre group was avoided to ensure stimulation of the fibre group only at or very close to the cathode. Below $1.5 \mathrm{~T}$ for a fibre group, the response latency for the fibre group was enhanced, while above $5 \mathrm{~T}$ the response latency decreased distinctly. Between 1.5-5 T, the response latency was quite constant. Because of short distances (37-42 mm) between stimulating cathode and first recording electrode, this kind of approach was extremely important for high conduction velocities, i.e. low threshold fibres. For CV below $10 \mathrm{~m} / \mathrm{s}$, the above mentioned factors do not lead to large discrepancies in $\mathrm{CV}$ calculation. Table 1 gives a list of the results obtained on efferents and afferents of different nerves. The results are described in detail below.

Table 1. Conduction velocities in $\mathrm{m} / \mathrm{s}$ (mean values with standard deviation) of different nerve fibres of the mouse hindlimb.

\begin{tabular}{|c|c|c|c|c|c|c|}
\hline & Gr. I aff. & A $\alpha$ eff. & Gr. II aff. & $A \gamma$ eff. & Gr. III (Aס) aff. & Gr. IV (C) aff. \\
\hline$P B$ & $\begin{array}{c}42.9 \pm 4.3 \\
(\mathrm{n}=3 ; \mathrm{p}<0.05)\end{array}$ & & $\begin{array}{c}20.3 \pm 5.7 \\
(n=4)\end{array}$ & & 9 & 0.8 \\
\hline$T i b$ & $\begin{array}{c}47.4 \pm 3.1 \\
(\mathrm{n}=20 ; \mathrm{p}<0.05)\end{array}$ & $\begin{array}{c}38.5 \pm 4.0 \\
(\mathrm{n}=8 ; \mathrm{p}<0.05)\end{array}$ & $\begin{array}{c}30.3 \pm 4.9 \\
(n=12)\end{array}$ & $\begin{array}{c}16.7 \pm 3.0 \\
(n=6)\end{array}$ & $\begin{array}{c}12.7 \pm 2.3 \\
(n=8)\end{array}$ & $\begin{array}{c}0.8 \pm 0.1 \\
(n=11)\end{array}$ \\
\hline Sur & $\begin{array}{c}43.8 \pm 3.8 \\
(n=12 ; p<0.01)\end{array}$ & $\begin{array}{c}39.3 \pm 3.1 \\
(\mathrm{n}=6 ; \mathrm{p}<0.05)\end{array}$ & $\begin{array}{c}28.8 \pm 4.0 \\
(n=9)\end{array}$ & $\begin{array}{c}12.0 \pm 0.8 \\
(n=4)\end{array}$ & $\begin{array}{c}14.7 \pm 3.1 \\
(n=5)\end{array}$ & $\begin{array}{c}0.8 \pm 0.03 \\
(n=7)\end{array}$ \\
\hline Per & $\begin{array}{c}55.2 \pm 6.1 \\
(\mathrm{n}=11)\end{array}$ & $\begin{array}{c}46.7 \pm 4.7 \\
(n=8)\end{array}$ & $\begin{array}{c}27.6 \pm 4.6 \\
(n=9)\end{array}$ & $\begin{array}{c}22.2 \pm 4.4 \\
(n=6)\end{array}$ & $\begin{array}{c}13.6 \pm 2.8 \\
(n=6)\end{array}$ & $\begin{array}{c}0.9 \pm 0.03 \\
(n=9)\end{array}$ \\
\hline
\end{tabular}

The left column gives the corresponding nerve, which was stimulated or recorded from, and the upper row gives the fibre group. Afferent and efferent groups are indicated by abbreviations (aff., eff.). No values were gained for the efferents of PB. Group I is always meant for the fastest fibres of a nerve. Due to the short distance between stimulation and recording electrode and the very short PB nerve, large stimulus artefacts prevented a systematic investigation of slower afferents of this nerve with higher stimulus strength. Only in one experiment these afferents could clearly be recorded. The p-values in column 2 and 3 give the significance of the difference of these $\mathrm{CV}$-values compared to the always higher values of Per. 

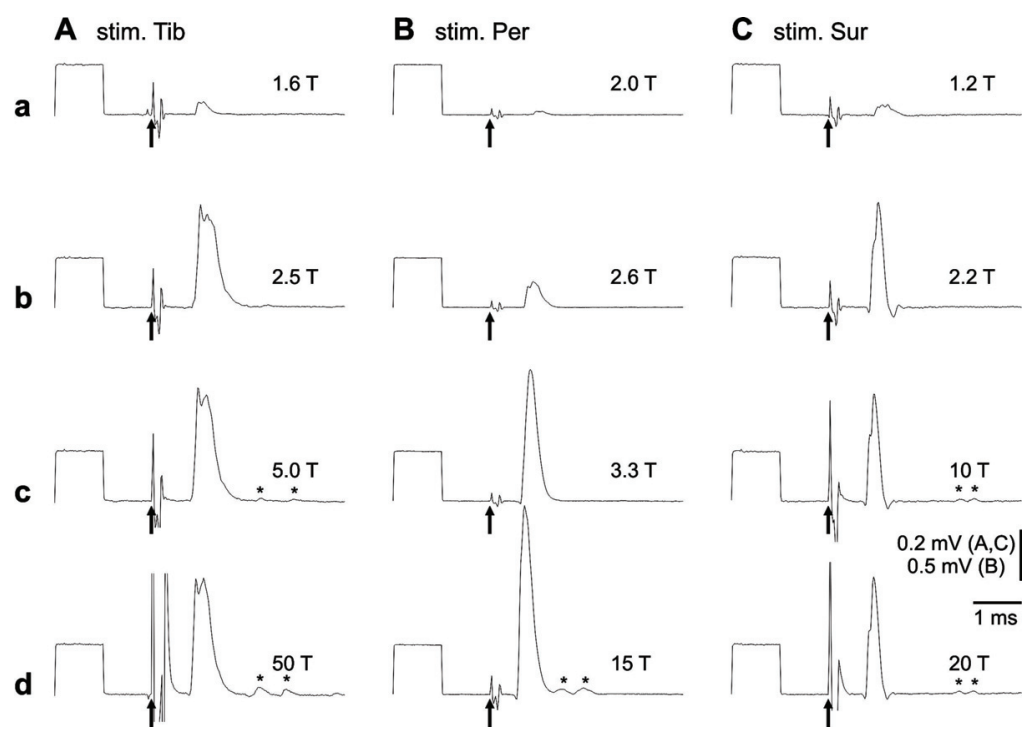

Fig. 1. Antidromic activation and recording of motor efferents of different hindlimb nerves. Stimulation of Tib (A), Per (B) and Sur (C); responses from the centrally cut VRL4. Stimulation near threshold for a-efferents (a) up to stimulation adequate for Y-efferents (d). Thresholds were calibrated for the lowest threshold afferents of the corresponding nerve. Latency measurements were performed with stimulation strengths like in (b). a-fibre responses with a double peak ( $A b-d)$ or a shoulder (Bb, Cc), indicating a faster and a slower a-fibre group. Stimulation strengths in the upper range elicit responses of fibres with velocities in the range of $\mathrm{y}$-fibres (*). The latter responses are often also double peaked. Note that in mice the sural nerve is containing efferents, too. Arrows indicate stimulation time. Records were averaged (8 consecutive responses each); sampling rate during recording was $50 \mathrm{kHz}$. Rectangle stimulation pulses, onset marked by an up-arrow, duration $0.1 \mathrm{~ms}$ (stimulation interval $1.84 \mathrm{~s}$ for all), except for Ad, where the stimulation pulse was $0.2 \mathrm{~ms}$ wide.

\section{Motor efferents}

To get information about motor efferents, either ventral root L4 was cut at its spinal cord entry and electrically stimulated, while a muscle nerve was recorded, or a muscle nerve was electrically stimulated, and we recorded from the cut end of the ventral root L4. Figure 1 shows examples for responses of $\alpha$ - and $\gamma$-efferents of Tib, Per and Sur. Responses of efferents were always found in all 3 nerves indicating that the sural nerve is not a pure cutaneous nerve like it is in cat (see below). Stimulating with graded strength and recording from efferents in many cases, especially for Tib efferents, gave some indications for two groups of $\alpha$-efferents (Fig. 1A), reflecting a faster (possibly phasic) and a slower (possibly tonic) group of motor efferents. With stimulation strengths of $5 \mathrm{~T}$ (Fig. 1Ac) and higher, slower motor efferents could be activated with responses which were small compared to those of $\alpha$-fibres and which conduct in the range of $\gamma$-fibres. In this experiment, the conduction lengths were for Tib $37 \mathrm{~mm}$, for Per $35 \mathrm{~mm}$ and for Sur $33 \mathrm{~mm}$. Accordingly, the MECV for the fast $\alpha$-fibres were $38.5 \pm 4.0 \mathrm{~m} / \mathrm{s}$ (Tib), $46.7 \pm 4.7 \mathrm{~m} / \mathrm{s}$ (Per), and $39.3 \pm 3.1 \mathrm{~m} / \mathrm{s}$ (Sur), and for the slower $\gamma$-fibres were $16.7 \pm 3.0 \mathrm{~m} / \mathrm{s}$ (Tib), $22.2 \pm 4.4 \mathrm{~m} / \mathrm{s}$ (Per) and $12.0 \pm 0.8 \mathrm{~m} / \mathrm{s}$ (Sur) (see Table 1). Strikingly, the velocities for Per were higher than for Tib and Sur for both $\alpha$ - and $\gamma$-fibres in every experiment. We were not able to measure MECV for $\mathrm{PB}$ efferents. Although we performed measurements from $\mathrm{PB}$ afferents with recordings from dorsal roots, reliable recordings from ventral roots while stimulating the PB failed.
Efferent motor fibres in the sural nerve (Fig. 2 and Supplementary Video)

The existence of efferent motor fibres in the sural nerve was approved by stimulation of the sural nerve which induced a ventrally directed twitch of the small toe (Supplementary Video) which could be approved by the EMG (Fig. 2C). This twitch persisted after cutting the sural nerve centrally (Fig. 2C) and it persisted after peripheral cutting of the smaller lateral branch of the sural nerve (Fig. 2D) but disappeared after the medial branch had been cut (Fig. 2E). In the experiment shown in Figure 2 the latency between proximal stimulation of the sural nerve and the response at the distal ENG recording electrode at the nerve was $0.22 \mathrm{~ms}$; the distance between the stimulating cathode and the ENG electrode was $6 \mathrm{~mm}$ (cf. Fig. 2A). This means a conduction velocity of the approved efferent fibres in the sural nerve of $37 \mathrm{~m} / \mathrm{s}$. This is in the range determined before (see above). The distance between the stimulating cathode and the entrance of the nerve into the M. flexor digiti minimi was $24 \mathrm{~mm}$ (cf. Fig. 2A), the distance from the entrance to the EMG electrode approximately $3 \mathrm{~mm}$. The latency between the stimulus and the beginning of the EMG wave was $1.82 \mathrm{~ms}$. With a conduction velocity of $37 \mathrm{~m} / \mathrm{s}$ (see above) the conduction time for the $24 \mathrm{~mm}$ to the muscle would be $0.65 \mathrm{~ms}$. Thus, the residual latency, which includes the synaptic delay and the time for the conduction with reduced velocity in the fine nerve fibre branches in the muscle and over the muscle fibres, amounts to $1.17 \mathrm{~ms}$. This value is well in the range which has been determined before (0.726-1.375 ms, Reed 1984). 


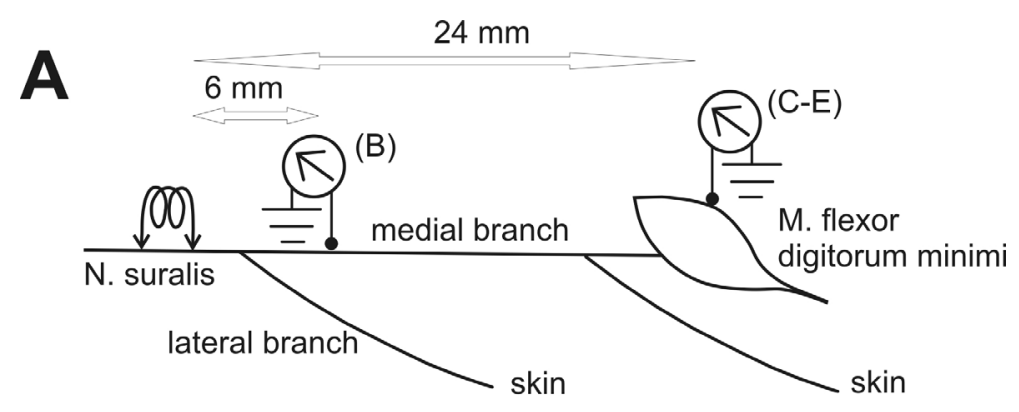

B ENG N. suralis

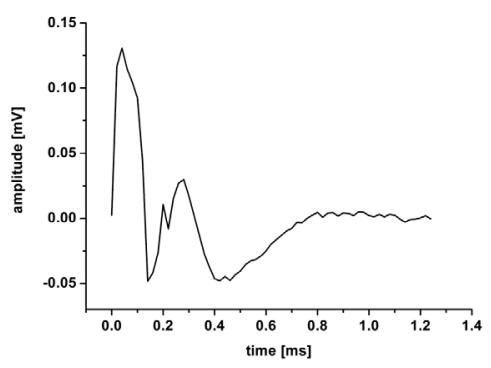

C emg m. flex. dig. min.; N. sural intact

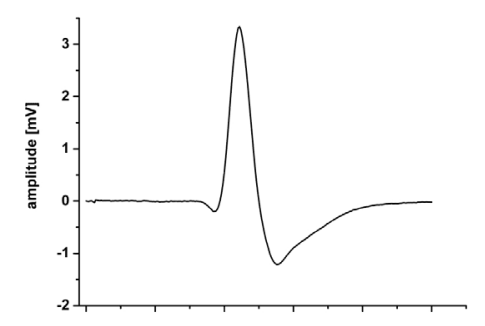

D emg M. flex. dig. min.; lat. branch of N. suralis cut

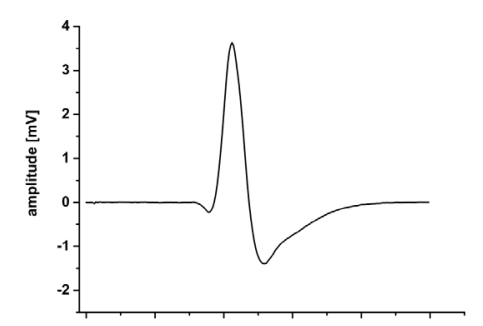

E emg m. flex. dig. min.; lat.+ med. branch of N. suralis cut

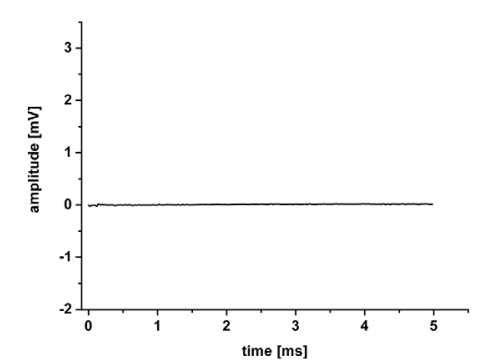

Fig. 2. Motor efferents in the sural nerve (see also Supplementary Video). Stimulation of the sural nerve; (A) experimental setup, (B) peripheral recording of the ENG of the sural nerve, (C-E) EMG recording of $M$. flexor digiti minimi. The EMG response occurred as long as the sural nerve was intact or the nerve was cut proximally to the stimulation electrode (C) or only the smaller lateral branch of the nerve was cut distally to the stimulation electrode (D), but EMG response disappeared when the medial branch of the nerve was distally cut (E).
Supplementary video (in on-line version only). This video sequence (lasts 15 seconds) shows some twitches of the small toe by contraction of M. flexor digiti minimi induced by recurrent stimulation of the sural nerve (see also Fig. 2).

\section{Muscle afferents}

The common Per, the Tib and the Sur contain afferents of both muscles and the skin. It is generally impossible to get pure responses of muscle afferents from these nerves with electrical stimulation. Responses from the dorsal root L4 always led to potentials with multiple shoulders and peaks representing the different fibre groups when stimulating those nerves with graded stimulation. The same was true when the dorsal root L4 was stimulated and the antidromic potential was recorded

from the nerves. The only pure muscle nerve we prepared was the $\mathrm{PB}$, and the responses had distinct peaks for group I to group IV afferents (Fig. 3). The fastest group I afferents in the shown example had MACV of $45.3 \mathrm{~m} / \mathrm{s}$ (Fig. 3A) and may be attributed to group Ia afferents and possibly some group Ib fibres (cf. Discussion). The whole range of MACV of $\mathrm{PB}$ was $39-46 \mathrm{~m} / \mathrm{s}$ over all experiments. Single shoulders of the peaks may represent single fibres of each group. The fastest MACV which was observed when stimulating the dorsal root and 
recording from the sciatic nerve was $47 \mathrm{~m} / \mathrm{s}$. In the example of Figure 3B presumed group II afferents (cf. Discussion) appeared with a threshold of about $1.6 \mathrm{~T}$ and a latency of $1.32 \mathrm{~ms}$ and had a MACV of $23.1 \mathrm{~m} / \mathrm{s}$.

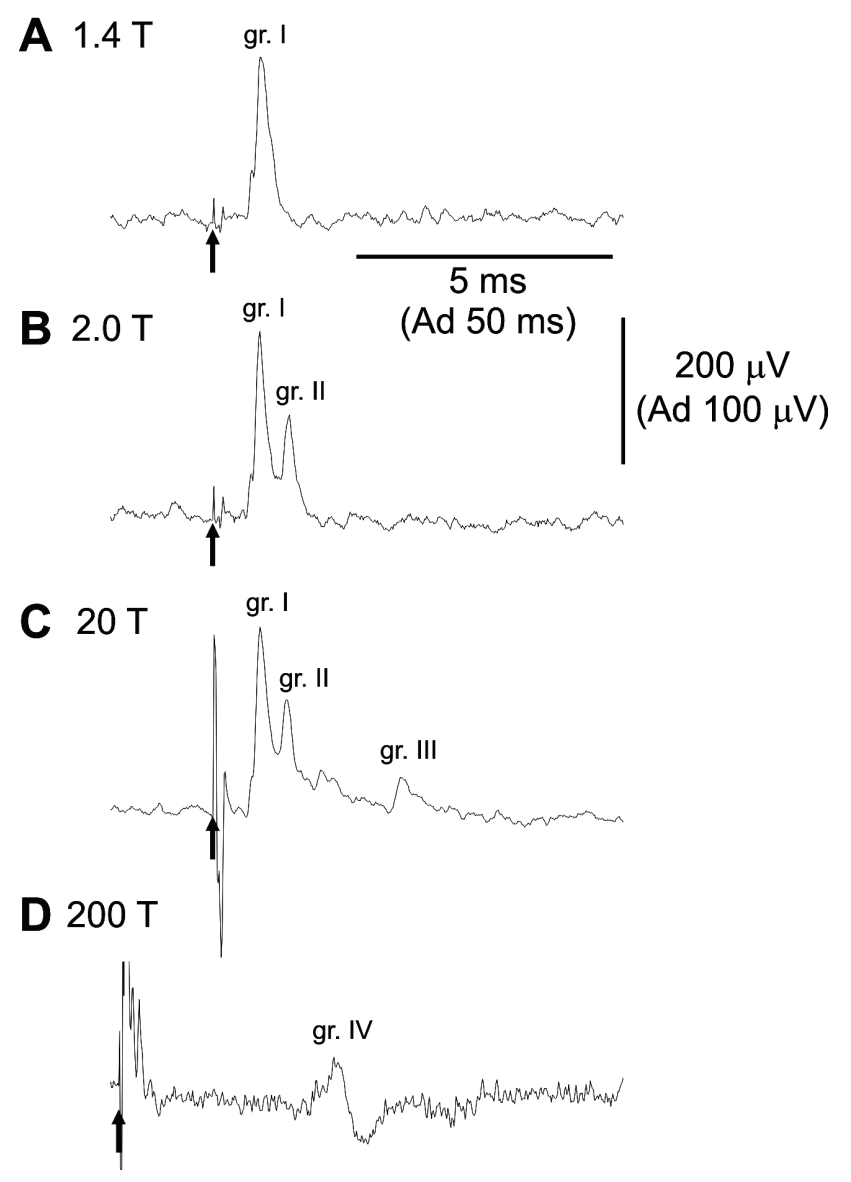

Fig. 3. Afferent fibre groups of the PB. Stimulation of the PB and recording of DRL4 with different stimulation strengths. The threshold stimulation strength was adjusted to the threshold of the PB afferents. The threshold for PB afferents was about 1.2 times of the threshold for the lowest threshold afferents in the sciatic nerve. All responses were averaged (8 responses each). Sampling rate in $\mathbf{A}-\mathbf{C}$ was $50 \mathrm{kHz}$, in D $10 \mathrm{kHz}$. Rectangle stimulation pulses of $0.1 \mathrm{~ms}$ duration for all stimulations except for $\mathbf{D}$, where $0.2 \mathrm{~ms}$ were used, onset marked by an up-arrow. The interval between stimulations was $1.84 \mathrm{~s}$ for all, except for $\mathrm{C}$ and $\mathrm{D}$ where the interval was $3.84 \mathrm{~s}$.

Responses of a further group of muscle afferents appeared after a latency of $3.44 \mathrm{~ms}$ (Fig. 3C); the threshold of this peak was around $7 \mathrm{~T}$, and the MACV of the fastest fibres of this group was $8.9 \mathrm{~m} / \mathrm{s}$. Therefore, these fibres may be assumed to belong to group III. This fibre group did not follow stimulation of higher frequencies, and therefore, the peak of this group better appeared with lower stimulation rates (here $3.84 \mathrm{~s}$ interval).

Unmyelinated afferents can often hardly be detected. However, in our experiments we have been successful in most cases for muscle and cutaneous afferents, when the duration of the stimulus was enhanced to at least $0.2 \mathrm{~ms}$ and the inter-stimulus interval was increased to at least $3 \mathrm{~s}$. Additionally, the short distances kept the dispersion of the potentials small. The example in Figure 3D shows the response of group IV muscle afferents. It appeared after a latency of about $38 \mathrm{~ms}$, thus the MACV was $0.8 \mathrm{~m} / \mathrm{s}$, and the corresponding fibres can be assumed to belong to group IV. Although group IV was much slower than group III, and the dispersion of the signal from different fibres was much higher, the amplitude was in the range of that of group III fibres. This is probably due to the fact that (at least in the cat) the number of group IV afferents considerably outnumbers the number of group III afferents (Boyd and Davey 1968). This may compensate for the fact, that action potentials of unmyelinated fibres are small compared to action potentials of group III fibres.

A further analysis of the MACV of group I muscle afferents of Tib, Per and Sur was performed and compared with that of PB. Regarding the mixed responses from cutaneous and muscle afferents, the first deflections of the potentials as shown for example in Figure 4 may be assumed to originate from group I muscle afferents. In our example, MACV for the Tib group I afferents was $47.9 \mathrm{~m} / \mathrm{s}$ (A) or $48.4 \mathrm{~m} / \mathrm{s}$ (B), both measured at $1.8 \mathrm{~T}$. The average MACV of the Ia afferents was $47.4 \mathrm{~m} / \mathrm{s}(\mathrm{n}=20$, S.D. $\pm 3.1 \mathrm{~m} / \mathrm{s}$, range $42.9-52.4 \mathrm{~m} / \mathrm{s})$ for Tib, $55.2 \mathrm{~m} / \mathrm{s} \quad(\mathrm{n}=11$, S.D. $\pm 6.1 \mathrm{~m} / \mathrm{s}$, range 45.6-63.4 m/s) for Per and $43.8 \mathrm{~m} / \mathrm{s}$ (n=12, S.D. $\pm 3.8 \mathrm{~m} / \mathrm{s}$, range $37.8-51.1 \mathrm{~m} / \mathrm{s}$ ) for Sur. Strikingly, group I afferents of Per (from mainly phasic muscles) were significantly faster than the afferents from other nerves (see Table 1, mean values are given \pm standard deviation (S.D.), statistical significance $(\mathrm{p}<0.05)$ was determined using ANOVA followed by Tukey test).

\section{Afferents of mixed nerves}

In mixed cutaneous/muscle nerves, our experiments do not allow a distinction to be made between muscle afferents slower than group I and cutaneous afferents. As mentioned above, Sur is a mixed nerve in mice. A large spectrum of conduction velocities was found between the group I range and the typical group III range. Because the single peaks were not very prominent and often provided only a shoulder within the declining potential, a continuum of conduction velocities formed the main potential, exposing some not very 
A stim. Tib, rec. DRL4

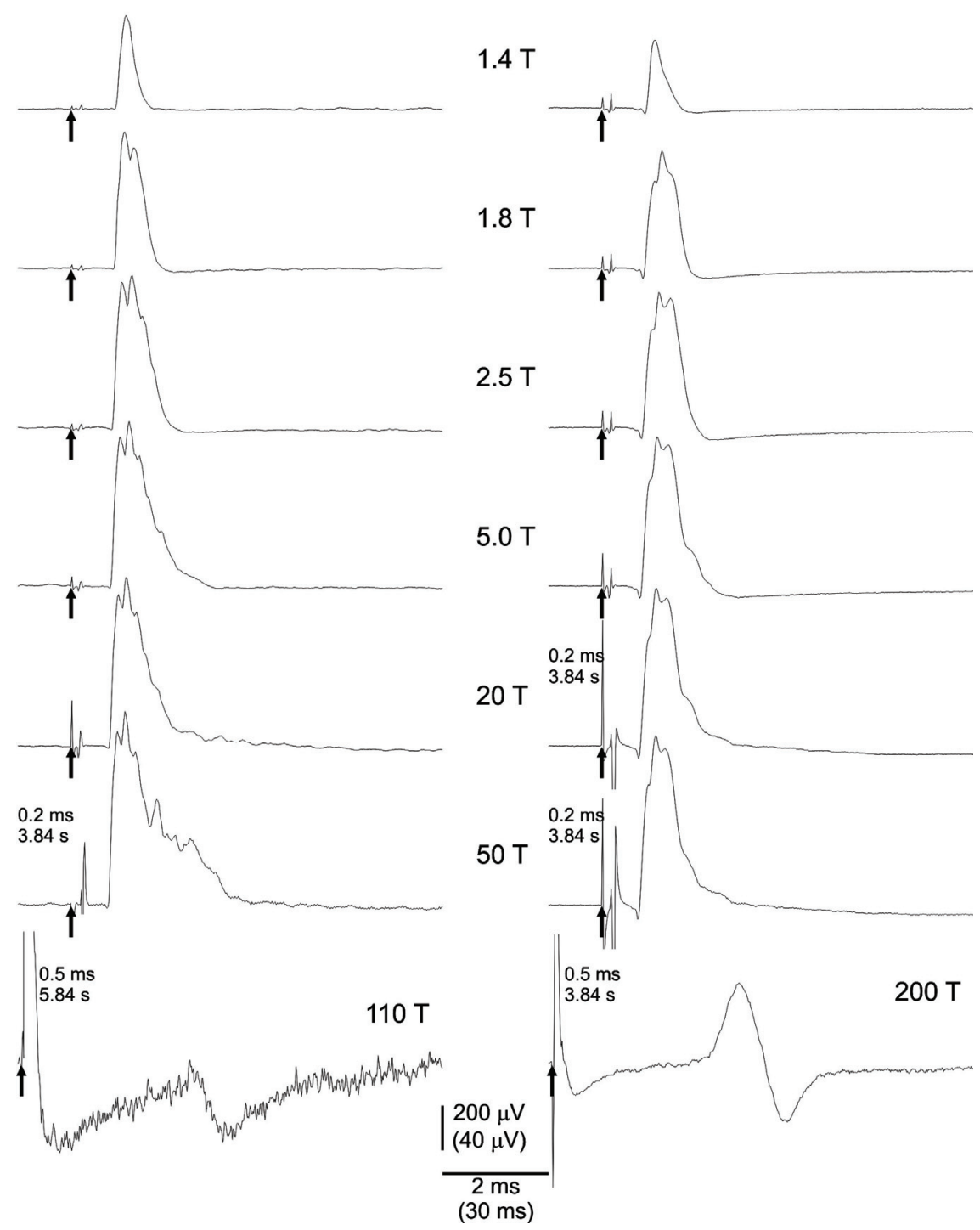

Fig. 4. Comparison of responses to ortho- and antidromic stimulation of afferents of a mixed nerve. Tib (A) and DRL4 (B) were stimulated with graded strength up to group IV (C-fibre) activation. In $A$, the stimulus-recording distance was $38 \mathrm{~mm}$, in $B$, the distance was $37.5 \mathrm{~mm}$. Averaged responses, (8 responses each). Rectangle stimulus pulses $(0.1 \mathrm{~ms}, 1.84 \mathrm{~s}$ recurrence frequency when not marked differently), onset marked by an up-arrow. Calibration of the bottom traces are put in parentheses. prominent focal points. Potentials appearing at thresholds of about 1.8-2 $\mathrm{T}$ and higher may be associated with group II fibres (cf. Discussion). As shown in Figure 3, the group II peak in a muscle nerve is a distinct one, but small compared to the group I peak. We may therefore assume that the large potential appearing after the group I peak in mixed nerves (Fig. 4) is mainly of cutaneous group II origin, associated with CACV of $30.3 \pm 4.9 \mathrm{~m} / \mathrm{s}$ for Tib, $28.8 \pm 4.0 \mathrm{~m} / \mathrm{s}$ for Sur, and $27.6 \pm 4.6 \mathrm{~m} / \mathrm{s}$ for Per.

$\mathrm{CV}$ between 10 and $15 \mathrm{~m} / \mathrm{s}$ was always associated with thresholds of $7.5 \mathrm{~T}$ or higher. This group of afferents may be assigned to group III afferents. However, in mixed nerves like the tibial nerve a differentiation between muscle and cutaneous afferents was impossible, and, moreover, there was no real separation between peaks of group II and group III origin. Below $10 \mathrm{~m} / \mathrm{s}$ there was a large gap down to about $1 \mathrm{~m} / \mathrm{s}$ and less. The response patterns shown in Figures 4A and 4B comprise some differences due to the different stimulus/recording conditions. In B, the only fibres which were recorded from were Tib fibres, irrespective of the stimulation strength. In $\mathrm{A}$, with higher stimulation strength, the stimulation possibly also spread to branches of the nerve not on the elctrodes, including fibres of the triceps surae and of flexor digitorum longus. These added to the response of the root as it contains also all or at least most afferents of these nerves. Thus, the latency of the beginning of the response potential originating from group I fibres shortened, and the amplitude of this response still increased with increasing stimulus strength well above group I maximum (cf. Fig. 4A, $20 \mathrm{~T}$ to $50 \mathrm{~T}$ ). This effect would not affect the latency of responses of higher threshold afferents (or at least not to the same extent) since the current spread centrally to the cathode is 
probably not strong enough to exceed their threshold. As mentioned above the possible effect of current spread would also not affect the determination of the $\mathrm{CV}$ of fast fibres because it was done with low stimulus strength $(\leq 2 \mathrm{~T})$.

The group IV (group C) afferents with conduction velocities of $1 \mathrm{~m} / \mathrm{s}$ and less were well circumscribed (Fig. 4A and B, $110 \mathrm{~T}$ and $200 \mathrm{~T}$ ), although a differentiation between muscular and cutaneous afferents is impossible here. The average CV of this group is $0.87 \mathrm{~m} / \mathrm{s}(\mathrm{n}=28$, S.D. $\pm 0.05 \mathrm{~m} / \mathrm{s}$, range $0.78-1.01 \mathrm{~m} / \mathrm{s})$. This CV was reduced, when the dorsal root was blocked by TTX $(0.540-0.544 \mathrm{~m} / \mathrm{s})$, according to earlier findings in the rat (Steffens et al. 2001). Generally, the better method to record the compound action potential of unmyelinated fibre groups of mixed nerves is the antidromic method with the nerves being peripherally cut and with stimulation of the dorsal root and recording of the peripheral nerve, because the potentials from the whole dorsal root are always contaminated by tonic spindle afferent activity from intact nerves coming through this dorsal root. This tonic activity partly also provided for the noisy recording line in Figure 4A at $110 \mathrm{~T}$.

\section{Discussion}

We have determined the $\mathrm{CV}$ of afferent and efferent nerve fibres of the hindlimb of the mouse in vivo. For that purpose a set-up was developed to keep a laminectomised mouse with dorsal and/or ventral roots and hindlimb nerves prepared for electrophysiology for several hours, and to stimulate and record different parts of the exposed nervous structures. To get reliable data, it was necessary to keep the mouse in a reasonable state for a longer period (several hours). Okada et al. (2001) as well as Ellrich and Wesselak (2003) touch this problem and particularly the second mentioned publication provides for valuable information concerning this special point.

In mice, distances to determine $\mathrm{CV}$ are up to $42 \mathrm{~mm}$ for the longest nerves used (Tib or Per). An error of maximally $4 \mathrm{~mm}$ of the in situ measurement of the distance between stimulating and recording electrode would lead to errors of maximally $\pm 10 \%$ of the $\mathrm{CV}$. This error adds to the inaccuracies done by the recording device: When the sampling rate is chosen too low, e.g. $20 \mathrm{kHz}$, which is enough for humans or cats, $\pm 6 \%$ inaccuracy adds to the result when we have a $\mathrm{CV}$ of about
$50 \mathrm{~m} / \mathrm{s}$ and $40 \mathrm{~mm}$ distance. The inaccuracy increases with shorter nerves like PB. The problem of the short distances has already been addressed (Biscoe et al. 1977). Some differences found in the literature for afferents and efferents of mice may possibly be ascribed to this problem. Particularly, if, as often done, the CV of the fastest motor efferents in vivo was determined by electrical stimulation with percutaneously inserted needle electrodes at two points (sciatic nerve and the distal tibial nerve) and EMG recording of the foot the exact site of stimulation is not quite clear. If then in addition the distance is only measured at the surface of the leg the results may differ to some extent. This difference may become crucial if pure transcutaneous stimulation was performed with surface electrodes $(26 \mathrm{~m} / \mathrm{s}$ for fastest motor efferents, Haupt and Stoffel 2004). Moreover, the technique with two point nerve stimulation and EMG recording did only allow for determination of the fastest motor efferents.

Concerning the accuracy of length measurements, uncovering the nerve and roots while leaving them in situ after death of the animal seems to be the more adequate method to get reliable results. The method used in in vitro studies, where the roots and/or nerves are completely dissected inhere the problem of possible shrinkage (von Burg et al. 1979) of the nerve or elongation, particularly of very thin nerves like Sur. Some problem of current spread with higher stimulus strengths from bipolar stimulation at the nerve, as done in our experiments, can not be excluded. However, such an effect on the determination of the $\mathrm{CV}$ of a fibre group could be excluded since the CVs were determined with stimulus strengths close to the threshold of the fibre groups.

The method to measure time differences between either two stimulation sites (for EMG recording) or between two recording sites has the advantage of eliminating the inaccuracy emerging from the unknown utilization time of the stimulus. However, with stimulus strengths of at least 1.5 times higher than the threshold and with $0.1 \mathrm{~ms}$ stimulus duration the stimulation is well above threshold. Therefore, in our experiments a utilization time of less than $0.05 \mathrm{~ms}$ (for the fast fibres) can be assumed. For an example of $40 \mathrm{~mm}$ nerve length and $1 \mathrm{~ms}$ conduction time this would mean an underestimation of the conduction velocity of less than $5 \%$.

Despite the different stimulation and recording techniques the values for the fastest motor efferents determined in our experiments are roughly in a 
comparable range as those of most former investigators $(45.9 \pm 7.21 \mathrm{~m} / \mathrm{s}$, Low and McLeod 1975; 46 $\pm 5 \mathrm{~m} / \mathrm{s}$, Sima and Robertson 1978; about $38 \mathrm{~m} / \mathrm{s}$, Toyoshima et al. $1986 ; 38.2 \pm 6.3 \mathrm{~m} / \mathrm{s}$, Huxley et al. $1998 ; 46.5 \pm 2.5 \mathrm{~m} / \mathrm{s}, \mathrm{Ng}$ et al. 1998; $40 \mathrm{~m} / \mathrm{s}$, Wallace et al. 1999; 41.5-50.5 m/s, Tabata et al. 2000; $53 \pm 8 \mathrm{~m} / \mathrm{s}$, Weiss et al. 2001; $47.13 \pm 3.28 \mathrm{~m} / \mathrm{s}$, Song et al. 2003; see however also Hirst et al. 1979 , up to $70 \mathrm{~m} / \mathrm{s}$ and Biscoe et al. 1977 , $10-100 \mathrm{~m} / \mathrm{s}$ in dorsal roots, $50-70 \mathrm{~m} / \mathrm{s}$ in ventral roots), whereby the more recent investigations demonstrated that transgenic mice or pathological mouse strains with myelin or metabolic disorders may develop a distinct reduction of the nervous $\mathrm{CV}$, partly even without distinct behavioural disorders. Most of those investigations concentrated on the fastest motor efferents, while our technique also enabled the determination of the $\mathrm{CV}$ of afferent fibres and of slower fibre groups, which could be compared to the $\mathrm{CV}$ of fast efferent motor fibres in the same experiment. Some of the discrepancies between the values of the mentioned investigations and our results may probably be explained by differences of the methods as mentioned above. If there might have been an influence of the age of adult mice on the MCV is not quite clear. Significantly slower MCV for mice of an age of 69-90 days compared to mice over 100 days old have been claimed (Huizar et al. 1975, Robertson and Sima 1980). Other authors did not find a correlation between age and MCV (Huxley et al. 1998). Mice under the age of 30 days seem to show clearly slower CACV of the peripheral nerve fibres than their adult counterparts (Koltzenburg et al. 1997, Weiss et al. 2001).

It can be presumed that group Ia fibres contribute to the group of the fastest and lowest threshold afferent fibres. However, a contribution of group Ib fibres can not be excluded. At least, even in the cat with its longer conduction distances a certain differentiation between the groups Ia and Ib by threshold and conduction velocity is only possible in the proximal muscle nerves e.g. PBSt, but not in the more distal muscle nerves e.g. GS (Bradley and Eccles 1953, Eccles et al. 1957, Laporte and Bessou 1957). When the fibre groups of muscle afferents in the mouse are not completely different from those in the cat, it can be assumed that the second wave occurring with increasing stimulus strength and some longer latency after the group I are group II afferents. Like in the cat the presumed group II afferents in mice (1) had a threshold around group I maximum, (2) had their maximum between around 5 and $10 \mathrm{~T}$ and (3) had a conduction velocity around $60 \%$ of the group I afferents
(Eccles and Lundberg 1959, Fu et al. 1974, Fu and Schomburg 1974). In this context it should be mentioned that particularly in the higher threshold group II range a certain fraction of group II muscle afferents may originate not from muscle spindles but from free nerve endings (for a review see Schomburg 1990). At least in the rat higher numbers of group II afferents and even some group I afferents from muscles may originate from free nerve endings (Hnik and Payne 1965, 1966). Corresponding to group II muscle afferents group III and group IV muscle afferents were classified by their threshold and conduction velocity (Eccles and Lundberg 1959, for review see Schomburg 1990).

Because the temperature in the oil pools of the hindlimb and at the spinal cord was in the lower thirties it cannot be excluded that the determined $\mathrm{CVs}$ are somewhat underestimated. However, since at least $80 \%$ of the length of the measured nerves was in situ running deep in the tissue between the muscles, that means in an environment with a temperature close to body core temperature of $37{ }^{\circ} \mathrm{C}$ it can be assumed that the determined values are close to the normal CVs. At least, even in the living animal the temperature in the more distal parts of the limb is lower than the core temperature. According to investigations in cat (Paintal 1965), the reduction of the conduction velocity of myelinated nerve fibres induced by a reduced temperature from $36{ }^{\circ} \mathrm{C}$ to $32{ }^{\circ} \mathrm{C}$ would be about $15 \%$. This means, that a conduction velocity of $40 \mathrm{~m} / \mathrm{s}$ measured at $32{ }^{\circ} \mathrm{C}$ would be about $46 \mathrm{~m} / \mathrm{s}$ at $36{ }^{\circ} \mathrm{C}$. However, since in our experiments only $20 \%$ of the nerve length of about $40 \mathrm{~mm}$ was exposed to lower temperatures it can be assumed that the calculated conduction velocities in our experiments were only less than 1.2-1.5 m/s underestimated.

Another error could arise from the fact that in our experiments, compared to most others, part of the conduction is via the spinal roots and for the afferents additionally via the spinal ganglion. In the dorsal roots centrally to the root ganglia a reduced conduction velocity of between $43 \%$ (Loeb 1976) and $82 \%$ (Czéh et al. 1977), both values determined in cat, of the peripheral conduction velocity was observed. Assuming a reduction to about $60 \%$ (mean value between those two values) and about $5 \mathrm{~mm}$ conduction in the roots (about $12.5 \%$ of the conduction distance) this would mean an underestimation of the peripheral conduction velocity for the fastest afferents of roughly $2 \mathrm{~m} / \mathrm{s}$ and for the slowest fibres of less than $0.15 \mathrm{~m} / \mathrm{s}$. Additionally, the conduction 
via the spinal root ganglion is delayed by approximately $0.1 \mathrm{~ms}\left(0.07-0.11\right.$ at $5{ }^{\circ} \mathrm{C}$ in the frog, Dun 1955; $0.1 \mathrm{~ms}$ in the rabbit, Mac Leod 1958) which would result in another underestimation of the calculated peripheral conduction velocity of afferent fibres of about $9 \%$. According to a missing intercalated ganglion, the determination of the conduction velocity of motor efferents was less affected by the included central part to the conduction distance.

The present data indicate that for the motor efferents as well as for the afferents it is necessary to distinguish between the different hindlimb nerves. This differentiation together with discrimination between $\alpha$-efferents and $\gamma$-efferents, and the finding that in mice the Sur contains fibres of the ventral root, presumingly $\alpha$ - and $\gamma$-efferents, and which may be species specific, are new. Concerning the afferents, the discrimination between cutaneous and muscle afferents is not possible with our method, unless the nerve tested is a pure muscle nerve or a pure cutaneous nerve. As mentioned, Sur has to be taken as a mixed nerve; however, PB can be taken as a pure muscle nerve.

\section{Conflict of Interest}

There is no conflict of interest.

\section{Acknowledgements}

This work was supported by a grant of the Deutsche Forschungsgemeinschaft (SCHO 37/16).

\begin{abstract}
Abbreviations
$\mathrm{CV}$, conduction velocity; CACV, cutaneous afferent conduction velocity; MECV, motor efferent conduction velocity; MACV, muscle afferent conduction velocity; $\mathrm{PB}$, posterior biceps; Per, common peroneal nerve; Sur, sural nerve; Tib, tibial nerve.
\end{abstract}

\section{References}

BISCOE TJ, HEADLEY PM, MARTIN MR, STIRLING CA: Electrophysiological observations on the spinal cord of the normal and dystrophic mouse. J Neurol Sci 31: 51-61, 1977.

BOYD IA, DAVEY MR: Composition of Peripheral Nerves. E and S LIVINGSTONE, Ltd., Edinburgh and London, 1968.

BRADLEY K, ECCLES JC: Analysis of the fast afferent impulses from thigh muscles. J Physiol (Lond) 122: 462-473, 1953.

CAIN DM, KHASABOV SG, SIMONE DA: Response properties of mechanoreceptors and nociceptors in mouse glabrous skin: an in vivo study. J Neurophysiol 85: 1561-1574, 2001.

CZEH G, KUDO N, KUNO M: Membrane properties and conduction velocity in sensory neurones following central or peripheral axotomy. J Physiol (Lond) 270: 165-180, 1977.

DIBAJ P, NADRIGNY F, STEFFENS H, SCHELLER A, HIRRLINGER J, SCHOMBURG ED, NEUSCH C, KIRCHHOFF F: NO mediates microglial response to acute spinal cord injury under ATP control in vivo. Glia 58: 1133-1144, 2010.

DIBAJ P, STEFFENS H, ZSCHÜNTZSCH J, NADRIGNY F, SCHOMBURG ED, KIRCHHOFF F, NEUSCH C: In vivo imaging reveals distinct inflammatory activity of the CNS microglia versus PNS macrophages in a mouse model for ALS. PLoS ONE 6: e17910, 2011.

DUN FT: Studies on the conduction of sensory impulses through the dorsal root ganglion in the frog. J Cell Physiol 38: 131-133, 1951.

ECCLES JC, ECCLES RM, LUNDBERG A: Synaptic actions on motoneurones in relation to the two components of the group I muscle afferent volley. J Physiol (Lond) 136: 527-546, 1957.

ECCLES RM, LUNDBERG A: Synaptic actions in motoneurones by afferents which may evoke the flexion reflex. Arch Ital Biol 97: 199-221, 1959.

ELLRICH J, WESSELAK M: Electrophysiology of sensory and sensorimotor processing in mice under general anaesthesia. Brain Res Protoc 11: 178-188, 2003.

FU TC, SANTINI M, SCHOMBURG ED: Characteristics and distribution of spinal focal synaptic potentials generated by group II muscle afferents. Acta Physiol Scand 91: 298-313, 1974.

FU TC, SCHOMBURG ED: Electrophysiological investigation of the projection of secondary muscle spindle afferents in the cat spinal cord. Acta Physiol Scand 91: 314-329, 1974. 
HAUPT WF, STOFFEL W: Nerve conduction velocity measurements reveal the functional deficit in ceramide galactosyl transferase-deficient (cgt-/-) mice. J Neurol Sci 217: 83-88, 2004.

HIRST DG, VOJNOVIC B, HOBSON B: Changes in nerve conduction velocity in the mouse after acute and chronic administration of nitroimidazoles. Br J Cancer 39: 159-167, 1979.

HNIK P, PAYNE R: Spontaneous activity in non-propioceptive sensory fibres from de-efferented muscles. $J$ Physiol (Lond) 180: 25-26, 1965.

HNIK P, PAYNE R: The origin of increased sensory outflow from chronically deafferented muscles. Physiol Bohemoslov 15: 498-507, 1966.

HUIZAR P, KUNO M, MIYATA Y: Electrophysiological properties of spinal motoneurones of normal and dystrophic mice. J Physiol (Lond) 248: 231-246, 1975.

HUXLEY C, PASSAGE E, ROBERTSON AM, YOUL B, HUSTON S, MANSON A, SABÉRAN-DJONIEDI D, FIGARELLA-BRANGER D, PELLISSIER JF, THOMAS PK, FONTES M: Correlation between varying levels of PMP22 expression and the degree of demyelination and reduction in nerve conduction velocity in transgenic mice. Hum Mol Genet 7: 449-458, 1998.

KOLTZENBURG M, STUCKY CL, LEWIN GR: Receptive properties of mouse sensory neurons innervating hairy skin. J Neurophysiol 78: 1841-1850, 1997.

LAPORTE Y, BESSOU P: Study of slow \& rapid subgroups of group I (afferent fibers of muscular origin of large diameter) in the cat (in French). J Physiol (Paris) 49: 1025-1037, 1957.

LOEB GE: Decreased conduction velocity in the proximal projections of myelinated dorsal root ganglion cells in the cat. Brain Res 103: 381-385, 1976.

LOW PA, MCLEOD JG: Hereditary demyelinating neuropathy in the Trembler mouse. J Neurol Sci 26: 565-574, 1975.

MAC LEOD P: Retardation of the conduction of afferent impulses in the spinal ganglion (in French). J Physiol (Paris) 50: 386-387, 1958.

NAKAGAWA M, MIYAGOE-SUZUKI Y, IKEZOE K, MIYATA Y, NONAKA I, HARII K, TAKEDA S: Schwann cell myelination occurred without basal lamina formation in laminin $\alpha 2$ chain-null mutant $\left(d y^{3 \mathrm{~K}} / d y^{3 \mathrm{~K}}\right)$ mice. Glia 35: 101-110, 2001.

NG DTF, LEE FK, SONG ZT, CALCUTT NA, LEE LW, CHUNG SSM, CHUNG SK: Effects of sorbitol dehydrogenase deficiency on nerve conduction in experimental diabetic mice. Diabetes 47: 961-966, 1998.

NORIDO F, CANELLA R, ZANONI R, GORIO A: Development of diabetic neuropathy in the C57BL/Ks (db/db) mouse and its treatment with gangliosides. Exp Neurol 83: 221-232, 1984.

OKADA H, HONDA M, ONO H: Method for recording spinal reflexes in mice: effects of thyrotropin-releasing hormone, DOI, tolperisone and baclofen on monosynaptic spinal reflex potentials. Jpn J Pharmacol 86: 134$136,2001$.

PAINTAL AS: Effects of temperature on conduction in single vagal and saphenous myelinated nerve fibres of the cat. J Physiol (Lond) 180: 20-49, 1965.

REED TE: Residual latency (delay at the neuromuscular junction): Normative values and heritability in mice. Behav Gen 14: 209-219, 1984.

ROBERTSON DM, SIMA AAF: Diabetic neuropathy in the mutant mouse [C57BL/ks(db/db)]. A morphometric study. Diabetes 29: 60-67, 1980.

SCHOMBURG ED: Spinal sensorimotor systems and their supraspinal control. Neurosci Res 7: 265-340, 1990.

SIMA AAF, ROBERTSON DM: Peripheral neuropathy in mutant diabetic mouse [C57BL/Ks (db/db)]. Acta Neuropathol (Berl) 41: 85-89, 1978.

SONG Z, FU DTW, CHAN Y-S, LEUNG S, CHUNG SSM, CHUNG SK: Transgenic mice overexpressing aldose reductase in Schwann cells show more severe nerve conduction velocity deficit and oxidative stress under hyperglycemic stress. Mol Cell Neurosci 23: 638-647, 2003.

STEFFENS H, HOHEISEL U, EEK B, MENSE S: Tetrodotoxin-resistant conductivity and spinal effects of cutaneous C-fibre afferents in the rat. Neurosci Res 39: 413-419, 2001.

TABATA H, IKEGAMI H, KARIYA K: A parallel comparison of age-related peripheral nerve changes in three different strains of mice. Exp Anim 49: 295-299, 2000. 
TOYOSHIMA E, YEAGER AM, BRENNAN S, SANTOS GW, MOSER HW, MAYER RF: Nerve conduction studies in the Twitcher mouse (murine globoid cell leukodystrophy). J Neurol Sci 74: 307-318, 1986.

VON BURG R, CONROY PJ, PASSALACQUA W: Peripheral electrophysiological parameters in mice treated with misonidazole. Br J Cancer 40: 134-143, 1979.

WALLACE MJ, BATT J, FLADD CA, HENDERSON JT, SKARNES W, ROTIN D: Neuronal defects and posterior pituitary hypoplasia in mice lacking the receptor tyrosine phosphatase PTPб. Nat Genet 21: 334-338, 1999.

WEISS MD, LUCIANO CA, QUARLES RH: Nerve conduction abnormalities in aging mice deficient for myelinassociated glycoprotein. Muscle Nerve 24: 1380-1387, 2001.

YOSHIDA S, MATSUDA Y: Studies on sensory neurons of the mouse with intracellular-recording and horseradish peroxidase-injection techniques. $J$ Neurophysiol 42: 1134-1145, 1979. 